\title{
0 canto de Miriam (Ex 15,20-21)
}

\section{Miriam's song (Ex 15,20-21)}

\author{
Matthias Grenzer* \\ Paulo Freitas Barros**
}

Resumo: Entre os discursos proferidos pelo homem no livro do Êxodo, o canto de Moisés (Ex 15,1c-18) é o mais extenso. Trata-se do primeiro canto nas Sagradas Escrituras de judeus e cristãos, veiculando uma oração de louvor ou exaltação. Surpreendentemente, por sua vez, o canto de Moisés, logo em seguida, é transformado em refrão, batuque e dança. Mais ainda: com o canto entoado por Miriam, acompanhada pelas demais mulheres, virando percussionistas e dançarinas, ocorre uma interessante alternância de gênero. Ou seja, de repente, vozes femininas se juntam às vozes de Moisés e dos filhos Israel, tornando o louvor mais completo e animado. Neste estudo apresenta-se uma análise exegética de Ex 15,20-21, texto originalmente composto em hebraico, envolvendo pesquisas linguísticas, literárias, históricas e, em especial, teológicas.

Palavras-chave: Êxodo; Miriam; Canto; Batuque; Dança.

Abstract: Among the speeches pronounced by man in the book of Exodus, the Song of Moses (Ex 15:1-18) is the longest one. It is the first chant in Holy Scripture of Jews and Christians that brings a prayer of praise and exaltation. Surprisingly, the Song of Moses was trans-

* Doutor em Teologia Bíblica e Mestre em História. Professor na Faculdade de Teologia da PUC-SP. Líder do Grupo de Pesquisa TIAT (Tradução e Interpretação do Antigo Testamento). E-mail: mgrenzer@pucsp.br.

** Mestre em Teologia Bíblica e membro do Grupo de Pesquisa TIAT (Tradução e Interpretação do Antigo Testamento). Professor no Instituto de Teologia da Diocese de São Miguel Paulista. E-mail: pfreitasbarros@yahoo.com.br. 
formed immediately into refrain, drumming and dance. Moreover, with the song sung by Miriam followed by other women, becoming percussionists and dancers, occurs an interesting shift of gender. Therefore, suddenly, the female voices join to the voices of Moses and Israel's sons, making the praise more animated and complete. This study is looking for an exegetical analysis of Ex 15:20-21, a text written in Hebrew. Therefore, it will involve linguistic, literary, historical and especially theological researches.

Keywords: Exodus; Miriam; Song; Drumming; Dance.

\section{Introdução}

Os dois versículos que formam o episódio do canto de Miriam (Ex 15,20-21) surpreendem o ouvinte-leitor do livro do Êxodo em diversos sentidos. 0 nome de Miriam é mencionado pela primeira vez na Bíblia. Ela também é a primeira mulher classificada como profetisa nas tradições do Antigo Testamento. Além disso, com Miriam, "no momento do ato central da salvação, na travessia do Mar dos Juncos, uma mulher é colocada ao lado de Moisés, a qual, como líder do povo", insiste "na interpretação decisiva” dos acontecimentos. ${ }^{1}$

Junto com Miriam, todas as mulheres, participantes da experiência do êxodo, entram em cena. Lideradas por ela, as demais realizam a primeira batucada na Bíblia, tocando seus tamborins. E, com o ritmo do batuque, as mulheres apresentam a primeira dança mencionada nas tradições bíblicas.

E as novidades não param por aqui. Junto com Moisés, Miriam entoa o primeiro canto na Bíblia, uma vez que os cantos de Labão nunca foram cantados, nem o tamborim de Labão foi tocado (Gn 31,27). Mais ainda, promovendo uma leitura continuada e sequencial das tradições bíblicas do início até o fim, os dois cantos em Ex 15 representam a "primeira oração comunitária cujo texto

1 FISCHER, Irmtraud. Gottesstreiterinnen, p. 179. 
é transmitido", sendo que as vozes formadas pelos dois gêneros se alternam, enquanto as leituras dos acontecimentos se entrelaçam. ${ }^{2}$

\section{Tradução}

Um estudo exegético de um episódio bíblico se inicia, em geral, com a tradução do texto a ser estudado, sendo que esta, no decorrer dos estudos, precisa ser constantemente revista e corrigida. ${ }^{3}$ Com isso, ocorre outro exercício importante. Chega-se à subdivisão ou segmentação das frases e/ou dos versículos. Ou seja, parte-se da ideia de que "é necessário reescrever o texto e subdividi-lo em linhas, como se ele fosse uma poesia”. ${ }^{4}$ No caso de Ex 15,20-21, após as primeiras linhas compostas em estilo épico, ouvindo-se a voz do narrador (v. 20a-21a), o discurso direto de Miriam apresenta um canto lírico, o qual trabalha com frases versificadas (v. 21b-d). Ambas as partes, a narração e o discurso direto em forma de poema, são composições artisticamente elaboradas e, por isso, precisam ser classificas como poéticas.

A tradução aqui apresentada observa, em especial, o verbo hebraico, com suas dimensões temporais e aspectuais. ${ }^{5}$ É, sobretudo, o verbo que, na língua hebraica, oferece determinado ritmo ao enunciado, promovendo, ao mesmo tempo, a segmentação e o avanço da narrativa composta por frases. Cada verbo, pois, apresenta uma ação ou descreve um estado. Além disso, na língua hebraica, as frases, especialmente nas partes de narração, começam comumente com o verbo. No entanto, há outros elementos linguísticos que funcionam como marcadores, influenciando a criação de unidades literárias e favorecendo, assim, a estruturação literária do texto.

2 FISCHER, Georg; BACKHAUS, Knut. Beten, p. 18.

3 UTZSCHNEIDER, Helmut; NITSCHE, Stefan Ark. Arbeitsbuch Literaturwissenschaftliche Bibelauslegung, p. 34-35.

4 SILVA, Cássio Murilo Dias da. Leia a Bíblia como literatura, p. 28.

5 Cf. GRENZER, Matthias. As dimensões temporais do verbo hebraico: desafio ao traduzir o Antigo Testamento. 
Seja ainda dito que, para destacar o objeto de estudo deste artigo, as citações bíblicas diretas encontram-se grafadas em itálico.

$\begin{array}{ll}\text { E Miriam, a profetisa, irmã de Aarão, tomou o tamborim em sua mão; } & 20 \mathrm{a} \\ \text { todas as mulheres saíram atrás dela, com tamborins e com danças. } & 20 \mathrm{~b} \\ \text { E Miriam lhes respondeu: } & 21 \mathrm{a} \\ \text { "Cantai ao Senhor, } & 21 \mathrm{~b} \\ \text { porque sublimemente se sublimou! } & 21 \mathrm{c} \\ \text { Lançou ao mar o cavalo e seu condutor". } & 21 \mathrm{~d}\end{array}$

\section{Estrutura literária}

\subsection{Contextualização}

Após a travessia do Mar dos Juncos, o povo dos filhos de Israel, finalmente, está livre. 0 opressor e seu exército, submergidos nas águas, ficaram para trás. A experiência surpreendente de salvação fez Israel experimentar o Senhor, seu Deus, como quem combate por seu povo $(\mathrm{Ex} 14,14)$. Com isso, logo após o momento de libertação do poder faraônico, Moisés, acompanhado pelos israelitas, entoa seu canto de louvor (Ex 15,1-18). Amplamente, celebra o ocorrido através de um poema épico, o qual destaca, de forma versificada, o que anteriormente tinha sido narrado, acolhendo imagens já trabalhadas.

Em princípio, com a finalização do canto de Moisés, ou seja, após a afirmação de que o Senhor reinaria para sempre e eternamente (Ex 15,18), o livro do Êxodo poderia iniciar a sequência daqueles episódios que apresentam a segunda parte do projeto do êxodo, contemplando a travessia do deserto por parte dos recém-libertados (Ex 15,22-Nm 21,20). Contudo, isso não acontece.

Surpreendentemente, a obra literária do livro do Êxodo, em estilo de narração, apresenta outra vez, embora de forma resumida, os acontecimentos no Mar dos Juncos (v. 19a-c). Assim, destacando novamente o mesmo contexto de salvação no Mar dos Juncos, situa as seguintes ações de Miriam e das outras mulheres (v. 20a-21a), sendo que estas resultam, após o canto de Moisés, mais extenso (Ex 15,1c-18a), no canto de Miriam, mais curto (v. 21b-d). 
Apenas após Miriam e as demais mulheres terem tocado seus tamborins e dançado, sendo que Miriam, através de seu canto, convidou a comunidade inteira a cantar ao Senhor, a primeira etapa do projeto do êxodo, correspondente à saída do Egito (Ex 12,37-15,21), chega literariamente a seu término. Ou seja, a experiência de salvação culmina em uma celebração, com batuque, dança e canto comunitário, liderada por uma mulher e suas companheiras, envolvendo, assim, os dois gêneros no louvor ao Senhor. Percebe-se, dessa forma, que a cena apresentada em Ex 15,19-21, ao ocupar o final da unidade literária de Ex 12,37-15,21, ganha literariamente maior destaque.

\subsection{Delimitação}

Após o término do discurso poético no canto de Moisés (Ex 15,1c-18), o livro do Êxodo volta a apresentar um trecho em prosa. Novamente, o ouvinte-leitor escuta a voz do narrador (v. 19a-21a). Justamente esta mudança de linguagem, do lírico ao épico, provoca uma delimitação. No caso, a primeira parte deste trecho de narração (v. 19) encerra a unidade literária anterior (Ex 15,1-19). A segunda parte, por sua vez - ver as três frases narrativas em v. 20a-b.21a -, inicia a nova unidade literária (Ex 15,20-21).

Isso ocorre, no entanto, porque as frases, em estilo de narração, introduzem, com Miriam e as demais mulheres, novas personagens (v. 19a-21a) e, ligado a isso, outro discurso direto, ou seja, o canto de Miriam (v. 21b-d). Acolhendo o início do canto de Moisés (Ex 15,1ce), variando apenas a forma do verbo, o novo canto faz prevalecer, outra vez, o estilo poético, sendo que o discurso é apresentado de forma versificada.

O canto de Miriam, por sua vez, termina, conforme se percebe na continuação, com o que é dito até v. 21d. A partir de Ex 15,22, pois, o livro começa a apresentar outro episódio, narrando a cena sobre a transformação das águas amargas em Mara (Ex 15,22-27), primeiro sinal da providência divina enquanto os israelitas atravessam o deserto. 


\subsection{Gênero literário}

Alguns textos na Bíblia Hebraica apresentam cenas em que mulheres saem com tamborins, danças e cantos, a fim de celebrarem, enfeitadas e cheias de alegria, uma vitória obtida num conflito bélico (Jz 11,34; 1Sm 18,6-7; Jr 31,4.13). Tais "grupos de mulheres transcendem a vida familiar ou doméstica e agem na esfera pública”, estando ligado a elas o "tambor-dança-canto do Antigo Israel”. ${ }^{6}$ Contudo, enquanto "tais danças e cantos se referem, de forma típica, a soldados que voltam vitoriosamente de batalhas, em Ex 15,20, este gênero é adaptado, funcionando como ação de graças pela salvação experimentada”, pois o Senhor tinha combatido por seu povo (Ex 14,14). ${ }^{7}$

Neste sentido, o canto de Miriam é um texto litúrgico que insiste no louvor a Deus. Trata-se de um "pequeno hino, arredondado em sua forma". ${ }^{8}$ Estão presentes os elementos do convite ao canto - Cantai ao Senhor! (v. 21b) -, a justificativa introduzida através do termo porque (v. 21c) e a parte central, o louvor (v. 21c-d), o qual "sempre se refere ao Senhor" e que, neste caso, "descreve uma determinada ação histórica do Senhor”. ${ }^{9}$

\section{Comentários}

\subsection{Miriam, a profetisa}

A primeira das catorze menções do nome de Miriam na Bíblia Hebraica - Ex 15,20.21; Nm 12,1.4.5.10. ${ }^{2 \times} 12$; $^{2 x}$ 20,1; 26,59; Dt 24,9; 1Cr 5,29; Mq 6,4 - ocorre no episódio aqui estudado. Chamada de profetisa (v. 20a) e apresentada como irmã de Aarão (v. 20a), Miriam "está simultaneamente envolvida em três atividades: dançar,

\footnotetext{
MEYERS, Carol. Maria, a artista, p. 251.

DOHMEN, Christoph. Exodus 1-18, p. 358.

8 UTZSCHNEIDER, Helmut; OSWALD, Wolfgang. Exodus 1-15, p. 338.

9 UTZSCHNEIDER, Helmut; NITSCHE, Stefan Ark. Arbeitsbuch Literaturwissenschaftliche Bibelauslegung, p. 232.
} 
tocar o tambor e cantar". ${ }^{10}$ Cada elemento dessa caracterização de Miriam merece maior atenção, a fim de vislumbrar a importância e as conotações desta personagem pertencente às tradições do êxodo.

Existem poucas mulheres profetisas na Bíblia Hebraica. Apenas Débora (Jz 4,4), Hulda (2Rs 22,14; 2Cr 34,22), Noadias (Ne 6,14) e a profetisa esposa de Isaías (Is 8,3) fazem companhia a Miriam. E, "além das palavras de Miriam em Ex 15,20s e Nm 12,1s, de Débora em Jz 4,6s.9.14; 5 e de Hulda em 2Rs 22,15-20, não é transmitido outro discurso de uma profetisa, sobretudo não em um livro específico de uma profetisa”."11

Nas tradições do êxodo, Miriam, por ser descrita como a profetisa, assemelha-se, primeiramente, a seus irmãos Moisés e Aarão. No caso, Moisés é descrito como profeta ímpar, ora por causa de o Senhor conhecê-lo face a face, ora por ele ter realizado sinais e prodígios na terra do Egito e feitos grandiosos e terríveis aos olhos de todo Israel (Dt 34,10-12). Também Aarão é chamado de profeta (Ex 7,1); como tal, sua tarefa consiste em falar ao povo no lugar de Moisés, tornando-se boca ou profeta deste último (Ex 6,16; 7,1).

Em princípio, as tradições do êxodo cultivam a esperança de a vocação profética poder caber a todos. Assim, o discurso de Moisés dirigido a Josué o favorece: Quem dera que todos do povo do Senhor fossem profetas, porque o Senhor concede seu espírito a eles! (Nm 11,29). Mais ainda, a repartição do espírito oferece a possibilidade da liderança partilhada, sendo que a função do profeta e da profetisa, os quais estão equipados com o mesmo espírito divino que estava sobre Moisés, consiste, por excelência, em insistir na dinâmica da libertação, conduzindo e guardando o povo em sua caminhada rumo à liberdade (Os 12,14). Neste sentido, é melhor ter lideranças multiplicadas. ${ }^{12}$ Além disso, jamais poderá faltar um sucessor profeta

10 MEYERS, Carol. Maria, a artista, p. 230.

11 KESSLER, Rainer. Mirjam und die Prophetie der Perserzeit, p. 87.

12 Cf. GRENZER, Matthias. Desejos inoportunos e a esperança por um povo profeta (Nm 11,4-35), p. 114-118. 
para Moisés (Dt 18,15.18), a fim de que a comunidade não fique como gado pequeno sem pastor (Nm 27,17).

Contudo, segundo as tradições do êxodo, existem também certos perigos que acompanham o fenômeno da atuação de profetas e profetisas. É possível, pois, que ocorram brigas entre eles. No caso, perdendo a humildade, profetas correm o risco de alegar que o Senhor falou com eles, sem que isso, de fato, tivesse ocorrido. Assim, motivados por interesses próprios, talvez queiram atingir o outro em vista de questões pessoais e nada decisivas em relação ao projeto e à vontade de Deus. Narra-se, neste sentido, como Aarão e Miriam provocaram um conflito grave com Moisés (Nm 12). ${ }^{13}$ No mais, o legislador israelita alerta em relação aos falsos profetas (Dt $13,2.4 .6 ; 18,20{ }^{2 \times} 22^{2 x}$ ). Quer dizer, nenhuma palavra que afasta 0 povo do compromisso exclusivo com o Senhor - o Deus que insiste na liberdade e sobrevivência digna de todos - poderia ser uma palavra autenticamente profética.

Enfim, no episódio aqui estudado, Miriam se apresenta como profetisa autêntica. Através de seu canto, realça a atuação do Senhor no momento do êxodo, sendo que esta experiência está nas origens da religião do antigo Israel.

\subsection{Irmã de Aarão}

Já em Ex 2,1-10, ouve-se ou lê-se que uma irmã de Moisés, junto com a filha do faraó e com a mãe de Moisés, consegue salvar, de forma corajosa, a vida de seu irmão. ${ }^{14}$ Contudo, essa narrativa não transmite o nome da irmã de Moisés. Apenas juntando as informações presentes em outros episódios é possível imaginar que tal irmã seja Miriam.

No Pentateuco, apenas uma só vez se descreve expressamente o parentesco entre os três irmãos líderes no projeto do êxodo: $O$ nome da mulher de Amram era Jocabed, filha de Levi, a qual nascerá para

\footnotetext{
13 Cf. GRENZER, Matthias. Brigas entre profetas (Nm 12,1-16), p. 127-147.

14 Cf. GRENZER, Matthias. Em defesa da criança (Ex 1,15-2,10), p. 24-30.
} 
Levi no Egito. Para Amram, ela gerou Aarão, Moisés e Miriam, a irmã deles (Nm 26,59). Além disso, como filhos do mesmo pai, os três ainda são mencionados em 1Cr 5,29. E, como enviados pelo Senhor, a fim de que, no momento do resgate do Egito, caminhassem à frente do povo, Moisés, Aarão e Miriam são lembrados conjuntamente em Mq 6,4.

Embora os três irmãos sejam chamados de profetas e profetisa, como visto acima, as tradições do êxodo parecem reservar um papel específico a cada um deles. No caso, Moisés representa a Torá, Aarão, o culto e Miriam, a profecia. Mais ainda: "Moisés e a Torá, a qual ele recebeu de Deus (Ex 20,18-21; Dt 5,22-33), encontram-se, com autoridade absoluta, acima da profecia; quer dizer, uma profecia paralela a Moisés ou contra ele corresponderia a uma blasfêmia". ${ }^{15}$ Assim, semelhantemente à profetisa Miriam, também o sacerdote e profeta Aarão é subjugado a Moisés (Ex 4,14-16; 7,1); inclusive o culto autêntico é aquele configurado de acordo com a Torá.

Enfim, os três irmãos estão presentes quando os filhos de Israel celebram sua liberdade recém-conquistada. Moisés canta (Ex 15,1). Miriam batuca e assume o refrão responsorial (v. 20a.21a). Aarão, por sua vez, somente figura como referência para Miriam. Talvez se trate da tentativa de "salvar a honra" dele ou de fazer um "reconhecimento de Aarão”, pois, de resto, ele “não é mencionado neste canto tão importante para Israel”. ${ }^{16}$

\subsection{Tamborins}

Primeiramente, Miriam toma o tamborim em sua mão (v. 20a). Depois, todas as mulheres saem atrás dela com tamborins (v. 20b). Ao imaginar, segundo a narrativa bíblica, que o povo do êxodo é formado por seiscentos mil varões a pé, sem contar aqueles que caminham a passos miúdos - ou seja, mulheres, crianças e animais

\footnotetext{
15 KESSLER, Rainer. Mirjam und die Prophetie der Perserzeit, p. 82.

16 DOHMEN, Christoph. Exodus 1-18, p. 357.
} 
- (Ex 12,37), a bateria constituída por todas as mulheres ganha dimensões gigantescas.

O instrumento "membranofone" é um "tambor de mão”, ou seja, um tamborim, no sentido de um "pequeno tambor de caixa portátil”. ${ }^{17}$ Imagina-se que cada mulher toque um só tamborim. Um detalhe de uma estela de Abidos, da época de Ramsés II (13011224 a.C.), mostra um grupo de mulheres que tocam seus tamborins enquanto participam de uma procissão religiosa. ${ }^{18}$

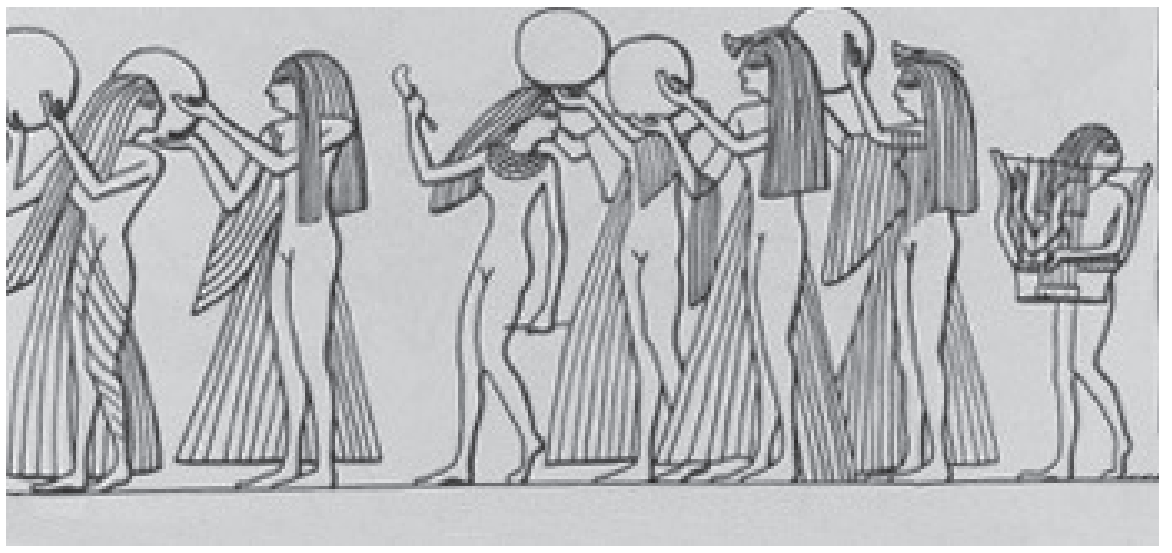

Também em Israel o tamborim acompanha festas e celebrações religiosas. Cabe aqui lembrar o momento do translado da arca para Jerusalém. Entre os diversos instrumentos musicais tocados por Davi e toda a casa de Israel, estão tamborins (2Sm 6,5; 1Cr 13,8). Os Salmos documentam, igualmente, o uso deste instrumento de batuque no ambiente do templo de Jerusalém. Nas procissões, por exemplo, cantores vão à frente; atrás, tocadores de instrumentos de corda; e, no meio, moças que tamborilam (Sl 68,25-26). No mais, a ordem de elevar um salmo se encontra acompanhada pela ordem de tanger um tamborim (Sl 81,3). Ou seja, salmodia-se e louva-se

\footnotetext{
17 MEYERS, Carol. Maria, a artista, p. 244.

18 KEEL, Othmar. Die Welt der altorientalischen Bildsymbolik und das Alte Testament, p. 315.
} 
o Senhor fazendo uso, dentre outros instrumentos musicais, do tamborim (Sl 149,3; 150,4).

Além disso, o tamborim está presente em outros ambientes, como por exemplo, quando um clã e/ou uma família tem algo a celebrar (Gn 31,27). Assim, o som do tamborim igualmente está presente nos banquetes dos que não se preocupam com os feitos do Senhor (Is 5,12) ou dos perversos (Jó 21,12). Além disso, ouve-se o toque do tamborim nos momentos em que o povo se propõe a expressar seu sentimento. Mulheres tocam tamborins ao saírem e irem ao encontro de quem volta, vitoriosamente, de um conflito bélico (Jz 11,34; 1Sm 18,6-7). Ou, no momento da reconstrução de Israel, a virgem é convidada a se adornar com o tamborim (Jr 31,4), sendo que o som dos tamborins, paralelamente, acompanha o castigo imposto ao opressor, como no caso da Assíria (Is 30,32). Em contrapartida, a experiência da catástrofe se caracteriza, justamente, pelo cessar da alegria dos tamborins (Is 24,8).

Quando Miriam toma o tamborim (v. 20a), sendo seguida pelas demais mulheres que também estão com seus tamborins (v. 20b), a batucada ganha conotação religiosa. O toque rítmico permite experimentar a vida pulsante e a alegria do povo, enquanto este, de forma surpreendente, experimenta a libertação do poder opressor, realizada pelo Senhor no Mar dos Juncos.

\subsection{Danças}

As mulheres que acompanham Miriam não saem apenas com tamborins atrás dela, mas também com danças (v. 20b). Onde se tamborila facilmente se dança, pois o ritmo convida o corpo a se movimentar (Jz 11,34; 1Sm 18,6; Jr 31,4; Sl 149,3; 150,4).

Segundo as tradições da Bíblia Hebraica, são sobretudo as mulheres que dançam: veja a filha de Jefté (Jz 11,34), as filhas de Silo (Jz 21,21.23), as mulheres que, diante de Saul, respondem com danças aos feitos de Davi (1Sm 18,6; 21,12; 29,5), a virgem de Israel 
(Jr 31,4.13) e a sulamita (Ct 7,1). No que se refere aos homens, apenas se ouve sobre os rodopios e saltos de Davi na frente da arca (2Sm 6,14.16; 1Cr 15,29) e sobre os dançarinos no monte Sião (Sl 87,7), os quais, com danças, louvam o nome do Senhor (Sl 149,3; 150,4).

A dança, em especial, é expressão de alegria, quando se experimenta a inversão de uma situação marcada por maiores sofrimentos. Neste sentido, o Salmo 114 convida a terra inteira a dançar diante do Senhor, por Israel ter saído do Egito (v. 1a.7b). ${ }^{19}$ Também as mulheres que acompanham Miriam são expressão do mistério de que o Senhor, ao insistir na liberdade dos oprimidos, é o Deus que transforma lamentação em dança (Sl 30,12).

No entanto, existe a possibilidade de o povo, talvez, dançar na frente de deuses feitos pelas próprias mãos, como o bezerro de ouro, atribuindo a conquista da liberdade a quem, na verdade, não está na origem dela (Ex 32,19). Com isso, distante do Senhor e da proposta feita por este Deus, o povo corre o risco de ver sua dança se converter, novamente, em luto (Lm 5,15). Enfim, a dança necessita da palavra que a interpreta. No caso do trecho aqui estudado, as palavras de Miriam que acompanham o som dos tamborins e as danças fornecem tal palavra decisiva.

\subsection{A sublimidade do Senhor}

O canto de Miriam destaca, inicialmente, a sublimidade do Senhor. Sublimemente, se sublimou - eis a tentativa de traduzir pleonasticamente a figura etimológica, sendo que, no hebraico, o verbo finito é acompanhado pela mesma raiz verbal no infinitivo absoluto (v. 1d). No entanto, quais são as conotações teológicas quando as tradições bíblicas imaginam a sublimidade do Deus de Israel?

A raiz verbal aqui traduzida por sublimar-se aparece pouco na Bíblia Hebraica. Além de sua quádrupla presença nos cantos de Moisés (Ex 15,1d²x) e Miriam (Ex 15,21²x), o profeta Ezequiel fala sobre

19 Cf. GRENZER, Matthias. O êxodo e a dança, p. 148-152. 
águas que se sublimam (Ez 47,5), sendo que o homem não consegue mais passar a pé por elas, mas somente nadando. No livro de Jó, o papiro se sublima, sendo que tal planta alcança, comumente, a altura de três metros (Jó 8,11). Além disso, a pessoa pode querer sublimar sua cabeça (Jó 10,16).

Observando, no entanto, na Bíblia Hebraica, as noventa e uma presenças dos seis substantivos e dos dois adjetivos derivados da mesma raiz verbal, a reflexão teológica sobre os contornos da $s u$ blimidade do Senhor, Deus de Israel, ganha um perfil mais nítido. Existe, pois, da parte do homem, a tentativa de sublimar-se. Esta sublimidade, por sua vez, se transforma geralmente em soberba, arrogância ou orgulho. Neste sentido, as tradições bíblicas focam a sublimidade dos maus (Jó 35,12), dos insolentes e tiranos (Is 13,11), dos fortes (Ez 7,24), dos perversos e jactanciosos (Sl 10,2; 73,6), dos que contam maldição e mentira (Sl 59,13), ocultam armadilhas (Sl 140,6) ou repartem despojos (Pr 16,19). Além disso, nações e/ou cidades insistem em sua sublimidade, tornando-se orgulhosas, soberbas e arrogantes: veja o Egito (Ez 30,6.18; 32,12), a Babilônia (Is 13,11.19; 14,11), a Assíria (Zc 10,11), Moab (Is 16,6; Jr 48,29; Sf 2,10), Amon (Sf 2,10), Tiro (Is 23,9), a Filisteia (Zc 9,6) e Sodoma (Ez 16,49). Também Israel (Ez 33,28; Os 5,5; 7,10; Na 2,3), Efraim (Is 9,8; 28,1.3), Judá (Jr 13,9.17), Jerusalém (Jr 13,9.17; Am 6,8) e a Samaria (Is 9,8; Am 6,8) não estão livres dessa tentação.

Com isso, percebe-se que, no que se refere à sublimidade, facilmente surgem conflitos. O próprio canto de Moisés, pois, insiste na abundância da sublimidade do Senhor (v. 1d.7a). Outras tradições bíblicas imaginam este Deus como quem monta céus e nuvens em sua sublimidade (Dt 33,26; Sl 68,35). Contudo, a glória da sublimidade divina, em determinadas circunstâncias, será experimentada como terror por parte do homem (Is 2,10). Afinal, ao vestir-se de sublimidade (Sl 93,1) e fazer coisa sublime (Is 12,5), o Senhor insiste, por excelência, na ação de deitar por terra a casa dos soberbos $(\operatorname{Pr} 15,25)$. 
Ou seja, cabe ao homem e às nações, inclusive a Israel, jubilar com a sublimidade deste Deus (Is 24,14), adotando uma postura contrária ao perverso, que não reconhece a sublimidade do Senhor (Is 26,10).

Enfim, o tema da sublimidade remete à questão da superioridade. Para Moisés e os filhos de Israel, após a experiência de salvação no Mar dos Juncos, não há mais dúvida a respeito da força maior e da sublimidade de quem combateu por eles.

\subsection{A ação do Senhor contra o poder militar faraônico}

O Senhor se sublimou justamente quando lançou ao mar o cavalo e seu condutor (v. 1e). Focando, primeiramente, o cavalo, este faz parte do Egito. A história de José, por exemplo, relata que, em tempos de miséria, cavalos podiam ser trocados por pão (Gn 47,17). Existia também o costume de reis estrangeiros comprarem, no Egito, cavalos para as suas tropas (Dt 17,16). No que se refere à narrativa do êxodo, por sua vez, com a peste dos animais, por ocasião da quinta praga, o Senhor já tinha atingido, entre os diversos animais do campo, também os cavalos egípcios (Ex 9,3). Mesmo assim, ao perseguir posteriormente os israelitas alforriados, o faraó leva todo cavalo dele consigo, a fim de compor, desta forma, as suas tropas (Ex 14,9.23).

Diante disso e pressupondo que especificamente cavalo e carro de guerra representam o poder militar do inimigo (Dt 20,1), os cantos de Moisés e Miriam destacam, em primeiro lugar, a ação do Senhor contra o cavalo (v. 1f.19a.21b; Dt 11,4). Quer dizer, este último, por Deus, foi lançado ao mar (v. 1e), semelhantemente a uma flecha lançada por um arqueiro (Sl 78,9).

Contudo, a ação divina não se dirige apenas contra animais ou equipamentos, pois, junto com o cavalo, também quem monta no animal ou no carro de guerra é atingido (v. 1e). No caso, seguindo a vocalização dos massoretas, lê-se o particípio ativo quem monta ou cavaleiro, e não o substantivo carro, derivado da mesma raiz verbal 
(v. 19a). Vale lembrar, porém, que, no exército egípcio, não se cavalga o cavalo, mas o cavalo é conduzido por quem está posicionado em pé no carro (v. 19a) ou na carruagem (v. 4a). Em todo caso, os cantos de Moisés e Miriam destacam "o aniquilamento de um poder militar ao qual pertencem pessoas, porque este poder parte de homens e é exercido por homens". ${ }^{20}$

Mais ainda: quem monta num cavalo ou carro de guerra se encontra numa posição elevada. Está mais alto e poderoso do que os demais, como quando o faraó fez José montar em seu segundo carro (Gn 41,43). Contudo, Moisés e Miriam celebram a fé de que, para salvar o seu povo, não há igual a Deus, o qual, para te ajudar, monta nos céus e, com sua sublimidade, nas nuvens (Dt 33,26). Ou seja, não importa a sublevação ou o poder do homem. Mesmo que esteja em uma posição mais alta, o Senhor sempre tem como derrubá-lo. ${ }^{21}$

\section{Considerações finais: Miriam como líder religiosa}

O episódio em Ex 15,20-21 apresenta Miriam, de várias formas, como quem assume liderança no momento de o evento do êxodo ser interpretado e celebrado. Primeiramente, quando ela toma $o$ tamborim em sua mão (v. 20a), todas as mulheres saem atrás dela, com tamborins e danças (v. 20b). "O entusiasmo de Miriam é contagiante e convida à imitação”. ${ }^{22}$ E a saída de todas as mulheres representa e ilustra o movimento do êxodo, sendo que o verbo sair funciona como uma palavra-chave ou um termo representativo no que se refere ao projeto de libertação. Enfim, "música e dança das mulheres expressam que o medo foi superado e que o caminho para fora está livre”. ${ }^{23}$

\footnotetext{
20 DOHMEN, Christoph. Exodus 1-18, p. 346.

21 FISCHER, Georg; MARKL, Dominik. Das Buch Exodus, p. 166.

22 FISCHER, Georg; MARKL, Dominik. Das Buch Exodus, p. 172.

23 UTZSCHNEIDER, Helmut; OSWALD, Wolfgang. Exodus 1-15, p. 337.
} 
Em segundo lugar, pode-se observar que a celebração da liberdade pelos anteriormente oprimidos ganha elementos novos. O que, até agora, era apenas canto (Ex 15,1-18) é reforçado com batuque e dança (v. 20a-b). Ou seja, após o evento surpreendente do êxodo, Miriam "faz as mulheres israelitas reagirem, por primeiro, com expressões não verbais, musicais e rítmicas, sendo que a palavra falada somente aparece em segundo lugar". ${ }^{24}$

Em terceiro lugar, na medida em que Miriam participa da celebração do êxodo, envolvendo todas as mulheres, ocorre uma alternância em relação aos gêneros. Primeiro, Moisés canta, junto aos filhos de Israel (Ex 15,1). Em seguida, Miriam batuca, faz as outras mulheres batucarem e dançarem (v. 20a-b). Finalmente, Miriam levanta sua voz e responde (v. 21a). Ou seja, ela reage "de forma espontânea" aos acontecimentos e ao canto de Moisés e dos filhos de Israel..$^{25}$ Com isso, o louvor de Deus, envolvendo os dois gêneros, é reforçado e "o texto-chave da libertação divina termina com um eco mais sonoro, semelhante a um gigantesco acorde final". ${ }^{26}$

Contudo, as palavras de Miriam não são excludentes. Pelo contrário, ela responde e convida a todos, homens e mulheres (v. 21a). Há dois sinais inequívocos nesse sentido. O sufixo pronominal ligado à preposição traduzido aqui como lhes (v. 21a) é masculino. Por isso, o texto deixa claro que Miriam responde também aos homens. Também o imperativo no plural - ver a expressão cantai em v. 21b - é masculino. Ou seja, o uso das formas masculinas chama realmente a atenção do ouvinte-leitor, pois, tanto no caso do sufixo pronominal como no caso do imperativo, a língua hebraica conhece formas femininas.

Enfim, Miriam ordena aos homens cantarem novamente. No entanto, desta vez eles são conduzidos por ela e pelas demais mulheres,

\footnotetext{
24 UTZSCHNEIDER, Helmut; OSWALD, Wolfgang. Exodus 1-15, p. 338.

25 ALBERTZ, Rainer. Exodus 1-18, p. 254.

26 FISCHER, Georg; MARKL, Dominik. Das Buch Exodus, p. 173.
} 
as quais, além de tamborilarem e dançarem (v. 20b), provavelmente também cantem, sendo que as formas no masculino do plural podem se estender, gramaticalmente, ao gênero feminino.

O canto proposto por Miriam, por sua vez, acolhe literalmente o início do canto de Moisés: Cantai ao Senhor, porque sublimemente se sublimou! Lançou ao mar o cavalo e seu condutor (v. 21b-d; Ex 15,1c-e). Ela apenas transforma a primeira palavra do canto de Moisés. Em vez de dizer quero cantar (Ex 15,1c), diz cantai (v. 21b). Com isso, Miriam assume liderança. Através do imperativo, surge uma relação entre Miriam e todos os participantes do êxodo, sendo que ela insiste na dinâmica de alargar o canto individual ao canto comunitário. Parece que todos, homens e mulheres, devam assumir agora as primeiras palavras do canto de Moisés como uma espécie de refrão. Com isso, ninguém fica de fora quando se trata de fazer uma leitura adequada dos acontecimentos e identificar a ação salvadora do Senhor.

\section{Bibliografia}

ALBERTZ, Rainer. Exodus 1-18. Zurique: Theologischer Verlag, 2012.

DOHMEN, Christoph. Exodus 1-18. Freiburg: Herder, 2015.

FISCHER, Irmtraud. Gottesstreiterinnen. Biblische Erzählungen über die Anfänge Israels. 3. ed. Stuttgart: Kohlhammer, 2006.

FISCHER, Georg; BACKHAUS, Knut. Beten. Würzburg: Echter, 2009.

FISCHER, Georg; MARKL, Dominik. Das Buch Exodus. Stuttgart: Katholisches Bibelwerk, 2009.

GRENZER, Matthias. As dimensões temporais do verbo hebraico: desafio ao traduzir o Antigo Testamento. Pistis \& Praxis: Teologia e Pastoral, Curitiba (PUC-PR), v. 8, n. 1, p. 15-32, 2016.

GRENZER, Matthias. Brigas entre profetas (Nm 12,1-16). In: GRENZER, Matthias. O projeto do êxodo. 2. ed. São Paulo: Paulinas. 2007, p. 127-147. 
GRENZER, Matthias. O êxodo e a dança. Salmo 114. In: FERNANDES, Leonardo Agostini; GRENZER, Matthias. Dança, ó terra! Interpretando Salmos. São Paulo: Paulinas, 2013, p. 137-152.

GRENZER, Matthias. Em defesa da criança (Ex 1,15-2,10). In: GRENZER, Matthias. O projeto do êxodo. 2. ed. São Paulo: Paulinas. 2007, p. 17-32.

GRENZER, Matthias. Desejos inoportunos e a esperança por um povo profeta (Nm 11,4-35). In: GRENZER, Matthias. O projeto do êxodo. 2. ed. São Paulo: Paulinas. 2007, p. 95-126.

KEEL, Othmar. Die Welt der altorientalischen Bildsymbolik und das Alte Testament. Am Beispiel der Psalmen. 5. ed. Göttingen: Vandenhoeck \& Ruprecht, 1996.

KESSLER, Rainer. Mirjam und die Prophetie der Perserzeit. In: KESSLER, Rainer. Gotteserdung. Beiträge zur Hermeneutik und Exegese der Hebräischen Bibel. Stuttgart: Kohlhammer, 2006, p. 81-88.

MEYERS, Carol. Maria, a artista. In: BRENNER, Athalya (org.). De Êxodo a Deuteronômio a partir de uma leitura de gênero. São Paulo: Paulinas, 2000, p. 229-254.

SILVA, Cássio Murilo Dias da. Leia a Bíblia como literatura. São Paulo: Loyola, 2007.

UTZSCHNEIDER, Helmut; NITSCHE, Stefan Ark. Arbeitsbuch Literaturwissenschaftliche Bibelauslegung. Eine Methodenlehre zur Exegese des Alten Testaments. 4. ed. Gütersloh: Gütersloher Verlagshaus, 2014.

UTZSCHNEIDER, Helmut; OSWALD, Wolfgang. Exodus 1-15. Stuttgart: Kohlhammer, 2013.

Recebido em: 12/04/2016 Aprovado em: 07/05/2016 